\title{
Reference ranges for antiepileptic drugs revisited: a practical approach to establish national guidelines
}

\author{
Arne Reimers ${ }^{1,2}$ \\ Jon Andsnes Berg ${ }^{3}$ \\ Margrete Larsen Burns ${ }^{4}$ \\ Eylert Brodtkorb ${ }^{5,6}$ \\ Svein I Johannessen ${ }^{6,7}$ \\ Cecilie Johannessen \\ Landmark $4,7,8$ \\ 'Department of Clinical Pharmacology, \\ St Olavs University Hospital, \\ Trondheim, Norway; ${ }^{2}$ Department \\ of Clinical and Molecular Medicine, \\ Norwegian University of Science \\ and Technology (NTNU), Trondheim, \\ Norway; ${ }^{3}$ Laboratory of Clinical \\ Biochemistry, Section of Clinical \\ Pharmacology, Haukeland University \\ Hospital, Bergen, Norway; \\ ${ }^{4}$ Department of Pharmacology, \\ Section for Clinical Pharmacology, \\ The National Center for Epilepsy, \\ Oslo University Hospital, Oslo, \\ Norway; ${ }^{5}$ Department of Neurology \\ and Clinical Neurophysiology, \\ St Olavs University Hospital, \\ Trondheim, Norway; ${ }^{6}$ Department \\ of Neuromedicine and Movement \\ Science, Norwegian University of \\ Science and Technology, Trondheim, \\ Norway; ${ }^{7}$ The National Center for \\ Epilepsy, Oslo University Hospital, \\ Oslo, Norway; ${ }^{8}$ Programme for \\ Pharmacy, Faculty of Health Sciences, \\ Oslo Metropolitan University, Oslo, \\ Norway
}

Correspondence: Arne Reimers

Department of Clinical Pharmacology,

St Olavs University Hospital, Pb 3250

Sluppen, 7006 Trondheim, Norway

Tel +47 72829109

Email arne.reimers@ntnu.no
This article was published in the following Dove Press journal:

Drug Design, Development and Therapy

Background and objective: Laboratories sometimes use different reference ranges for the same antiepileptic drug (AED), particularly for new and poorly investigated drugs. This may contribute to misunderstandings, concerns or inappropriate dose changes, which in turn may affect therapeutic effect, drug safety or treatment adherence. Therefore, the Norwegian Association of Clinical Pharmacology wished to update and harmonize the reference ranges for AEDs and establish national guidelines for Norway.

Methods: A working group collected information on the reference ranges used by Norwegian laboratories for all commonly used AEDs. These reference ranges were compared to recent recommendations by the International League Against Epilepsy, current literature, applicable clinical studies, reference ranges used by leading Northern European epilepsy centers outside of Norway, and routine data derived from Norwegian laboratory databases.

Results: Reference ranges varied between laboratories for four of 23 available AEDs (lamotrigine, valproate, eslicarbazepine and oxcarbazepine). For four AEDs (brivaracetam, perampanel, stiripentol and sulthiame), reference ranges had not previously been established. In total, 13 reference ranges were either harmonized, updated or newly established. No changes were applied to the remaining 10 AEDs.

Conclusion: Updated and harmonized reference ranges are now available for 22 of the 23 AEDs available in Norway. The exception is vigabatrin (reference range not applicable). Revision of reference ranges is an important part of pharmacovigilance of AEDs and must be a continuous process based on current literature and clinical experience.

Keywords: antiepileptic drug, serum concentration, reference range, therapeutic drug monitoring

\section{Introduction}

The use of antiepileptic drugs (AEDs) has been constantly increasing over many years, and the major part of this growth can be ascribed to psychiatric disorders and pain treatment. ${ }^{1-3}$ In 2016, there were 127,138 registered users of AEDs in the records of the Norwegian Institute of Public Health, corresponding to 24 users per 1,000 inhabitants. $^{3}$

Due to unfavorable pharmacokinetic properties, marked drug interaction potential and narrow therapeutic windows, therapeutic drug monitoring (TDM) of AEDs has traditionally been used to support and optimize epilepsy treatment. ${ }^{4,5}$ In Norway, TDM has been used as a part of the comprehensive care approach in epilepsy for 50 years. ${ }^{4}$ Reference ranges for first-generation AEDs (ie, introduced until 1984) are well established and almost uniform worldwide. ${ }^{5}$

In general, reference ranges for AEDs are as poorly documented as reference ranges for any medical drug. While there are some studies that have examined the 
correlation between dose and clinical effect of AEDs, studies that examine the correlation between serum concentration and clinical effect are scarce. Fortunately, almost all AEDs exhibit linear pharmacokinetics, meaning that their dose correlates proportionally with their serum concentration. Moreover, many AEDs have been in use for 30 years or longer, and clinical experience has led to broadly accepted reference ranges, even if they have not been studied systematically. Where such clinical data or experience is lacking, preliminary reference ranges may be calculated from concentration/dose ratios derived from Phase I and II studies and doses used in Phase III studies. Reference ranges may also be derived from routine data, for example, the central $90 \%$ or $95 \%$ of accumulated routine serum concentration measurements, although this method is less reliable for various reasons. ${ }^{6}$

Since 1989, 15 new or second-generation AEDs have been introduced. For the oldest among them (eg, lamotrigine), reference ranges may be regarded as equally well established as for the first-generation AEDs. For the more recent ones, however, there is a general paucity of data. The Commission on Antiepileptic drugs of the International League Against Epilepsy (ILAE) has issued recommendations for TDM during drug development. ${ }^{7}$ Yet, even if TDM may be used during clinical studies of new AEDs, serum concentrations collected in such studies are only rarely published. Thus, clinical data that could form an appropriate basis to define reference ranges are usually not available until years of clinical experience and routine measurements have elapsed. Consequently, reference ranges used by laboratories and in scientific publications may differ.

The Norwegian Association of Clinical Pharmacology launched in February 2015 a web-portal for all pharmacologic and toxicologic analyses that are available in Norway (The Pharmacology Portal). ${ }^{8}$ One of the goals is the nationwide harmonization of reference ranges used by the laboratories represented. A working group was established with the task to update and harmonize reference ranges for AEDs. This paper describes the workflow and the results of this process.

\section{Methods}

\section{Data collection}

The working group started the harmonization process by gathering information on AED reference ranges used by the largest laboratories in Norway. The data were collected from The Pharmacology Portal, from the laboratories' official websites and from direct contact with the laboratories.

The standard practice for TDM of AEDs in Norway is to use drug-fasting blood samples (ie, 12-24 hours after the last dose) taken at steady state. Accordingly, reference ranges are based on values from such samples. This ensures that serum concentration measurements and procedures are comparable in all parts of the country.

\section{Evaluation of the reference ranges}

Current reference ranges as shown in Table 1 were compared with guidelines for TDM of AEDs as proposed by the ILAE in 2008. ${ }^{5}$ Because this publication contains official ILAE recommendations, it was used as the main reference. Since 2008, several new AEDs have entered the market. A more recent review article that includes most of these new AEDs was used as another main reference. ${ }^{9}$ Additionally, other relevant primary and secondary literature was used (referenced in the Results section) following a systematic literature search in PubMed, with search terms including "antiepileptic drugs", "concentration", "reference range" and "therapeutic drug monitoring".

Where the literature was inconclusive and where we found considerable differences between established/ recommended reference ranges and the existing reference ranges in Norway, additional data were obtained from the routine TDM databases at St Olavs University Hospital (Trondheim), Haukeland University Hospital (Bergen), Oslo University Hospital (National Center for Epilepsy; Ullevål) and from the Filadelfia Epilepsy Hospital in Dianalund, Denmark. This included both published and unpublished data as well as personal communications. We also used information on reference ranges used by the laboratories of two leading German epilepsy centers, Bielefeld-Bethel and Kehl-Kork.

We then performed an overall assessment and evaluation of the available information for each individual AED, with emphasis on the degree of clinical evidence. Clinical studies on the correlation between dose or serum concentration and clinical effect were ranked highest, while retrospective, database-derived reference ranges were ranked lowest. The overall assessment also considered Scandinavian/Northern European treatment traditions and the fact that there is close collaboration and professional exchange between the Scandinavian countries. Care was taken to ensure that only data in accordance with Norwegian standards were used, that is, values from blood samples taken drug fasting and at steady state. All sources of information are referenced in detail for each AED.

\section{Results and discussion General}

The Board of the Norwegian Association of Clinical Pharmacology approved the final report submitted by the 
Table I Former and new reference ranges, given in molar units and mass units ${ }^{\mathrm{a}}$

\begin{tabular}{|c|c|c|c|c|c|}
\hline \multirow[t]{2}{*}{ Antiepileptic drug } & \multicolumn{2}{|c|}{ Former reference range ${ }^{b}$} & \multicolumn{2}{|c|}{ New reference range } & \multirow[t]{2}{*}{ Action performed } \\
\hline & $\mu \mathrm{mol} / \mathrm{L}$ & mg/L & $\mu \mathrm{mol} / \mathrm{L}$ & mg/L & \\
\hline Brivaracetam & NA & NA & $1-10$ & $0.2-2$ & Newly established \\
\hline Carbamazepine & $15-45$ & $4-11$ & $15-45$ & $4-11$ & None \\
\hline \multirow{2}{*}{$\begin{array}{l}\text { Free carbamazepine } \\
\text { Carbamazepine-10,II-epoxide }^{c}\end{array}$} & \multicolumn{4}{|c|}{$20 \%-30 \%$} & \multirow[t]{2}{*}{ None } \\
\hline & \multicolumn{4}{|c|}{$5 \%-15 \%$} & \\
\hline Clobazam $^{d}$ & $0.1-1$ & $0.03-0.3$ & $0.1-1$ & $0.03-0.3$ & \multirow[t]{2}{*}{ None } \\
\hline N-desmethylclobazam ${ }^{d}$ & $1-10$ & $0.3-3$ & $1-10$ & $0.3-3$ & \\
\hline Clonazepam $^{d}$ & $0.06-0.22$ & $0.019-0.069$ & $0.04-0.12$ & $0.013-0.038$ & Updated \\
\hline Eslicarbazepine & $\begin{array}{l}30-100 \\
50-140 \\
10-100 \\
45-140\end{array}$ & $\begin{array}{l}8-26 \\
13-36 \\
3-26 \\
12-36\end{array}$ & $12-100$ & $3-26$ & $\begin{array}{l}\text { Harmonized and } \\
\text { updated }\end{array}$ \\
\hline Ethosuximide & $300-600$ & $42-85$ & $280-700$ & 39-99 & Updated \\
\hline Felbamate & $125-250$ & $30-60$ & $125-250$ & $30-60$ & None \\
\hline Gabapentin & $20-120$ & $3-21$ & $20-120$ & $3-21$ & None \\
\hline Lacosamide & $10-40$ & $3-10$ & $10-40$ & $3-10$ & None \\
\hline Lamotrigine & $\begin{array}{l}10-50 \\
10-60\end{array}$ & $\begin{array}{l}3-13 \\
3-15\end{array}$ & $10-50$ & $3-13$ & Harmonized \\
\hline Levetiracetam & $30-240$ & $5-41$ & $30-240$ & $5-41$ & None \\
\hline Oxcarbazepine ${ }^{e}$ & $\begin{array}{l}45-140 \\
50-140\end{array}$ & $\begin{array}{l}12-36 \\
13-36\end{array}$ & $12-140$ & $3-36$ & $\begin{array}{l}\text { Harmonized and } \\
\text { updated }\end{array}$ \\
\hline Perampanel & NA & NA & $0.25-2.85$ & $0.1-1$ & Newly established \\
\hline Phenobarbital & $50-130$ & $12-30$ & $50-130$ & $12-30$ & None \\
\hline Phenytoin & $40-80$ & $10-20$ & $40-80$ & $10-20$ & None \\
\hline Free phenytoin & \multicolumn{4}{|c|}{$\leq 10 \%$} & \\
\hline Pregabalin & $10-30$ & $2-5$ & $10-35$ & $2-6$ & Updated \\
\hline Rufinamide & $20-130$ & $5-31$ & $15-130$ & $4-31$ & Updated \\
\hline Stiripentol & NA & NA & $15-95$ & $4-22$ & Newly established \\
\hline Sulthiame & NA & NA & $5-35$ & $2-10$ & Newly established \\
\hline Topiramate & $15-60$ & $5-20$ & $6-30$ & $2-10$ & Updated \\
\hline Valproate & $250 / 300-600 / 700$ & $36 / 43-87 / 101$ & $300-700$ & $43-101$ & Harmonized \\
\hline Free valproate & \multicolumn{4}{|c|}{$\leq 10 \%$} & \\
\hline Vigabatrin $^{f}$ & NA & NA & NA & NA & None \\
\hline Zonisamide & $45-180$ & $10-38$ & $45-180$ & $10-38$ & None \\
\hline
\end{tabular}

Notes: All serum concentrations apply to blood samples taken in drug-fasting and in pharmacokinetic steady state. Decimals rounded to nearest whole number except

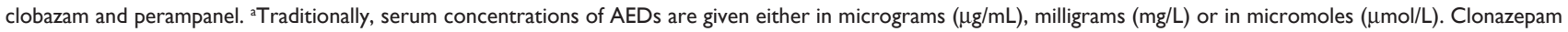
is usually given in nanograms $(\mathrm{ng} / \mathrm{mL})$ or nanomoles $(\mathrm{nmol} / \mathrm{L})$. Clonazepam has a minor role as an AED and is mostly used for psychiatric indications. As concentrations of most psychotropic drugs are given in $\mathrm{ng} / \mathrm{mL}$ or $\mathrm{nmol} / \mathrm{L}$, we suggest that clonazepam concentrations continue to be stated in $\mathrm{ng} / \mathrm{mL}$ or $\mathrm{nmol} / \mathrm{L}$. ${ }^{b}$ Former reference ranges were gathered from Norwegian laboratories using The Pharmacology Portal (www.farmakologiportalen.no). ${ }^{10}$ cConcentrations of carbamazepine-I0, II-epoxide are usually not

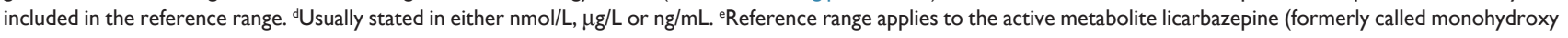
derivative, MHD). Vigabatrin is an irreversible enzyme inhibitor, and thus there is no direct correlation between serum concentration and effect.

Abbreviations: AED, antiepileptic drug; NA, not applicable.

working group. The new reference ranges are now officially acknowledged in Norway and The Pharmacology Portal has been updated..$^{10}$ The medical community was informed through the Journal of the Norwegian Medical Association. ${ }^{11}$

For most AEDs, the reference ranges used by Norwegian laboratories were either identical or similar. For some AEDs, considerable differences were found, most pronounced for eslicarbazepine and valproate (Table 1). Measurement of serum concentrations was available for a total of 18 out of 23 AEDs. Some analyses are currently under development; they were, therefore, included in this work.

Most reference ranges were suggested to be kept unchanged, or with minor adjustments only. For some AEDs, however, more significant changes were recommended. This is accounted for below. An overview of old and new updated reference ranges is given in Table 1. Note that all reference 
ranges are based on drug-fasting serum concentrations at pharmacokinetic steady state.

\section{Brivaracetam}

This is the most recently marketed AED. A method for measuring serum concentrations is currently under development at one of the laboratories represented in this paper. A reference range of $2.4-4.3 \mu \mathrm{mol} / \mathrm{L}(0.5-0.9 \mathrm{mg} / \mathrm{L})$ has recently been suggested. ${ }^{12}$ Recommended daily doses are 50-200 mg. Postmarketing studies show that doses above $200 \mathrm{mg} / \mathrm{d}$ may be safely used in epilepsy and status epilepticus. ${ }^{13-15}$ Pharmacokinetic data suggest that a daily dose of $2 \times 50 \mathrm{mg}$ will result in an average steady-state serum concentration of about 3.3-3.8 $\mu \mathrm{mol} / \mathrm{L}(0.7-0.8 \mathrm{mg} / \mathrm{L}) .{ }^{16}$ Brivaracetam has linear kinetics and dose proportionality can be assumed. ${ }^{16}$ Thus, $50 \mathrm{mg} / \mathrm{d}$ would be expected to yield 1.4-1.9 $\mu \mathrm{mol} / \mathrm{L}(0.3-0.4 \mathrm{mg} / \mathrm{L})$, while $200 \mathrm{mg}$ would be expected to result in about 6.6-8.5 $\mu \mathrm{mol} / \mathrm{L}$ (1.4-1.8 mg/L). Pharmacokinetic-pharmacodynamic modeling based on five Phase II and Phase III trials predicts a $50 \%$ seizure reduction from about $0.9 \mu \mathrm{mol} / \mathrm{L}(0.2 \mathrm{mg} / \mathrm{L}) .{ }^{17}$ Based on these data, we suggest a preliminary reference range of $1-10 \mu \mathrm{mol} / \mathrm{L}(0.2-2 \mathrm{mg} / \mathrm{L})$.

\section{Carbamazepine}

The reference range for carbamazepine of $15-45 \mu \mathrm{mol} / \mathrm{L}$ (4-11 mg/L) has been applied in Norway for decades. ILAE's therapy commission (2008) states 17-51 $\mu \mathrm{mol} / \mathrm{L}$ (4-12 mg/L). ${ }^{5}$ This is in line with other epilepsy centers, with only minor deviations. ${ }^{18-20}$ Data from the routine databases at St Olavs University Hospital and the National Center for Epilepsy show that $<6 \%$ of all serum concentrations are above $45 \mu \mathrm{mol} / \mathrm{L}$ (11 mg/L), which even includes overdose cases and intoxications (unpublished data). We, therefore, recommend keeping today's reference range unchanged.

Carbamazepine has a pharmacologically active metabolite (carbamazepine-10,11-epoxide) that is separately measured in many laboratories. The concentration of the epoxide metabolite is highly variable, also dependent on the comedication, but generally $5 \%-15 \%$ of the parent drug. ${ }^{9}$ The epoxide metabolite is usually not included in the reference range.

Measurement of free (unbound) carbamazepine is available at some laboratories. Usually, carbamazepine is about $70 \%-80 \%$ protein-bound and concentrations of the unbound fraction range from 4 to $12.5 \mu \mathrm{mol} / \mathrm{L}(1-3 \mathrm{mg} / \mathrm{L}){ }^{21}$

\section{Clobazam}

Clobazam is one of the older AEDs but has recently attracted more attention following the licensing of this drug in the USA.
The reference ranges of $0.1-1 \mu \mathrm{mol} / \mathrm{L}(0.03-0.3 \mathrm{mg} / \mathrm{L})$ for the parent substance and $1.0-10 \mu \mathrm{mol} / \mathrm{L}(0.3-3 \mathrm{mg} / \mathrm{L})$ for the active metabolite desmethyl-clobazam are well established and identical with the ILAE recommendations. ${ }^{5}$ Experience has shown that analysis of desmethyl-clobazam can be very useful. It fluctuates more than the parent compound and can indicate genetic mutations in CYP2C19.22 We recommend keeping these reference ranges unaltered.

\section{Clonazepam}

Clonazepam is marketed as an AED, but is also widely used for psychiatric indications. The former reference range in Norway for epilepsy was $60-220 \mathrm{nmol} / \mathrm{L}$ (20-70 ng/mL). This reference range has been used for many years, and is also currently recommended by ILAE..$^{5}$ There are, however, clinical data supporting a lower reference range of $48-160 \mathrm{nmol} / \mathrm{L}(15-50 \mathrm{ng} / \mathrm{mL}){ }^{23}$ The Filadelfia Epilepsy Hospital in Denmark uses 40-120 nmol/L (13-38 ng/mL) (J Borg Rasmussen, personal communication), and Bethel (Germany) 64-128 nmol/L (20-40 ng/mL). ${ }^{18}$ As clonazepam has a significant potential for misuse, our suggestion is changing the reference range to $40-120 \mathrm{nmol} / \mathrm{L}(13-38 \mathrm{ng} / \mathrm{mL})$.

\section{Eslicarbazepine}

Patsalos and Berry suggest $12-139 \mu \mathrm{mol} / \mathrm{L}(3-36 \mathrm{mg} / \mathrm{L}){ }^{9}$ This is identical to the suggested reference range for oxcarbazepine's active metabolite, licarbazepine (formerly called monohydroxy derivative, MHD). However, licarbazepine is a racemate consisting of $20 \% R$-licarbazepine and $80 \%$ $S$-licarbazepine (eslicarbazepine), and most of the pharmacologic effect is ascribed to eslicarbazepine. ${ }^{24}$ Thus, a $20 \%$ lower reference range would appear more appropriate. A recent clinical study by Svendsen et al that investigated the serum concentration/effect relation of eslicarbazepine proposes a reference range of $12-100 \mu \mathrm{mol} / \mathrm{L}(3-26 \mathrm{mg} / \mathrm{L}){ }^{25}$ This is in accordance with the results from pharmacokinetic/ pharmacodynamic modeling, ${ }^{26}$ and we suggest following their proposal.

\section{Ethosuximide}

Only two laboratories in Norway offer this analysis, and both used the same reference range of 300-600 $\mu \mathrm{mol} / \mathrm{L}$ (42-85 mg/L). ILAE suggests 283-708 $\mu \mathrm{mol} / \mathrm{L}$ (40-100 mg/L), based on two clinical studies that correlated serum concentrations with clinical effect. ${ }^{5}$ This range is also used by the two German epilepsy centers Bethel and Kork. ${ }^{18,20}$ In Denmark, 240-700 $\mu \mathrm{mol} / \mathrm{L}(34-100 \mathrm{mg} / \mathrm{L})$ is used. ${ }^{19}$ Our recommendation is, therefore, to change the current reference range in Norway to $280-700 \mu \mathrm{mol} / \mathrm{L}(39-99 \mathrm{mg} / \mathrm{L})$. 


\section{Felbamate}

Felbamate is infrequently prescribed, mainly because it may induce severe hepatotoxicity and bone marrow depression. Concentrations above $250 \mu \mathrm{mol} / \mathrm{L}(60 \mathrm{mg} / \mathrm{L})$ are associated with better therapeutic effect, but also with significantly higher prevalence of adverse effects. ${ }^{27}$ The reference range used in Norway is $125-250 \mu \mathrm{mol} / \mathrm{L}(30-60 \mathrm{mg} / \mathrm{L})$, which is identical to the ILAE recommendation. ${ }^{5}$ Bethel uses an upper bound of $336 \mu \mathrm{mol} / \mathrm{L}(80 \mathrm{mg} / \mathrm{L})$, while Kork uses a range of $85-190 \mu \mathrm{mol} / \mathrm{L}(20-45 \mathrm{mg} / \mathrm{L}) .{ }^{18,20}$ The available data are too ambiguous to justify a change; thus, we suggest keeping today's reference range.

\section{Gabapentin}

While some laboratories in Norway have used a reference range of $70-120 \mu \mathrm{mol} / \mathrm{L}(12-20 \mathrm{mg} / \mathrm{L})$, others have used $20-120 \mu \mathrm{mol} / \mathrm{L}(3-21 \mathrm{mg} / \mathrm{L})$, which is close to the values suggested by ILAE and the Bethel epilepsy center., ${ }^{5,18}$ The epilepsy center in Kork uses a lower upper limit of $60 \mu \mathrm{mol} / \mathrm{L}$ $(10 \mathrm{mg} / \mathrm{L}) .{ }^{20} \mathrm{~A}$ recent study showed that $35 \%$ of 189 patients with epilepsy had serum concentrations below $20 \mu \mathrm{mol} / \mathrm{L}$ $(3 \mathrm{mg} / \mathrm{L}) .{ }^{28}$ Preliminary data from the same center suggest that a large part of these low concentrations is most likely due to incomplete gastrointestinal absorption, a common phenomenon with gabapentin..$^{29}$ Although gabapentin is mostly prescribed for neuropathic pain, sufficient data to describe the correlation between serum concentration and degree of pain-relieving effect are not available. Still, a low serum concentration may be an indicator of poor clinical efficacy. As the current reference range of $20-120 \mu \mathrm{mol} / \mathrm{L}$ (3-21 mg/L) is close to the ILAE recommendation, we suggest keeping this unchanged until more data are available to allow for a re-evaluation. It should also be indicated by laboratories that this reference range applies to treatment of epilepsy.

\section{Lacosamide}

A reference range of $10-40 \mu \mathrm{mol} / \mathrm{L}(3-10 \mathrm{mg} / \mathrm{L})$ has so far been used in Norway. Patsalos and Berry suggest $40-80 \mu \mathrm{mol} / \mathrm{L}(10-20 \mathrm{mg} / \mathrm{L}),{ }^{9}$ but this is based on blood samples taken $0-3$ hours after intake. ${ }^{30,31}$ A Norwegian study with 344 patients and an Italian study with 75 patients found that nearly all patients with good therapeutic effect had drugfasting serum concentrations within a range of $10-40 \mu \mathrm{mol} / \mathrm{L}$ $(3-10 \mathrm{mg} / \mathrm{L}){ }^{32,33} \mathrm{We}$, therefore, recommend that the current reference range remains unchanged.

\section{Lamotrigine}

A reference range of either $10-50(3-13 \mathrm{mg} / \mathrm{L})$ or $10-60 \mu \mathrm{mol} / \mathrm{L}(3-15 \mathrm{mg} / \mathrm{L})$ has been stated by laboratories in Norway. ILAE (2008) recommends $10-60 \mu \mathrm{mol} / \mathrm{L}$ (3-15 mg/L), based on several studies. ${ }^{5}$ This recommendation was maintained by Patsalos and Berry. ${ }^{9}$ A large, retrospective Norwegian register study with more than 12,000 serum concentrations found that $40 \%$ of all samples were below $10 \mu \mathrm{mol} / \mathrm{L}(3 \mathrm{mg} / \mathrm{L})$, and $90 \%$ of all samples were below $30 \mu \mathrm{mol} / \mathrm{L}(8 \mathrm{mg} / \mathrm{L}){ }^{34}$ This was a database study without information on clinical efficacy, and included patients with psychiatric disorders. On the other hand, a study from Australia found that $75 \%$ of all samples were $27 \mu \mathrm{mol} / \mathrm{L}$ ( $7 \mathrm{mg} / \mathrm{L}$ ) or above..$^{35}$ The two leading German epilepsy centers use $12-55 \mu \mathrm{mol} / \mathrm{L}(3-14 \mathrm{mg} / \mathrm{L}$; Bethel) and $8-40 \mu \mathrm{mol} / \mathrm{L}$ (2-10 mg/L; Kork). In Denmark, 10-50 $\mu \mathrm{mol} / \mathrm{L}$ (3-13 mg/L) is used. ${ }^{18,20} \mathrm{We}$ recommend keeping the reference range at $10-50 \mu \mathrm{mol} / \mathrm{L}(3-13 \mathrm{mg} / \mathrm{L})$.

\section{Levetiracetam}

The current reference range in Norway is $30-240 \mu \mathrm{mol} / \mathrm{L}$ $(5-41 \mathrm{mg} / \mathrm{L})$. The lower limit is lower than that suggested by $\operatorname{ILAE}(70-270 \mu \mathrm{mol} / \mathrm{L} ; 12-46 \mathrm{mg} / \mathrm{L})$. The ILAE proposal is based on a retrospective database study that only included the highest doses used by each patient. ${ }^{36}$ On the other hand, two studies showed that $45 \%$ of all samples were below $70 \mu \mathrm{mol} / \mathrm{L}(12 \mathrm{mg} / \mathrm{L})$, and $80 \%$ of all samples were between 30 and $150 \mu \mathrm{mol} / \mathrm{L}$ ( 5 and $25 \mathrm{mg} / \mathrm{L})(\mathrm{n}=353$ [A. Reimers, unpublished data] and $n=300) .{ }^{37}$ Hence, we recommend no changes until there are adequate clinical data available.

\section{Oxcarbazepine}

Oxcarbazepine is pharmacologically active and, thus, not a prodrug according to standard definition. Thus, increased serum concentrations of oxcarbazepine may cause toxicity. For instance, co-administration with perampanel may reduce the clearance of oxcarbazepine. ${ }^{38}$ Usually, however, oxcarbazepine is rapidly biotransformed to its active metabolite licarbazepine (formerly called MHD). ${ }^{24,39}$ For that reason, the reference range applies to licarbazepine. In Norway, both 45 and $50 \mu \mathrm{mol} / \mathrm{L}$ ( 12 and $13 \mathrm{mg} / \mathrm{L}$ ) have been used as the lower limit, and $140 \mu \mathrm{mol} / \mathrm{L}(35 \mathrm{mg} / \mathrm{L})$ as the upper. ILAE recommends $12-140 \mu \mathrm{mol} / \mathrm{L}(3-36 \mathrm{mg} / \mathrm{L}) .{ }^{5}$ This corresponds well with the findings from Norwegian routine TDM databases (unpublished data). Our recommendation is, therefore, to reduce the lower limit to $12 \mu \mathrm{mol} / \mathrm{L}(3 \mathrm{mg} / \mathrm{L})$.

\section{Perampanel}

Data from clinical studies show that after repeated administration of 4 or $8 \mathrm{mg}$ per day, maximum serum concentrations $\left(\mathrm{c}_{\max }\right)$ average around 1,064 and $2,008 \mathrm{nmol} / \mathrm{L}$ (370 and $690 \mathrm{ng} / \mathrm{mL}$ ), respectively. ${ }^{40}$ After $10-12$ hours, distribution is 
complete and concentrations have fallen to $\sim 70 \%$ of $\mathrm{c}_{\max }$. One would, therefore, expect drug-fasting serum concentrations of $\sim 750-1,400 \mathrm{nmol} / \mathrm{L}$ (260 and $480 \mathrm{ng} / \mathrm{mL}$ ). The Bethel epilepsy center uses $143-4350 \mathrm{nmol} / \mathrm{L}(50-1,500 \mathrm{ng} / \mathrm{mL})$; this is classified as preliminary. ${ }^{18}$ The Epilepsy Hospital in Dianalund uses a preliminary range of $250-2,850 \mathrm{nmol} / \mathrm{L}$ (86-1,000 ng/mL; J Borg Rasmussen, personal communication). The Danish reference range is closer to the theoretically derived numbers. We suggest using this range until sufficient clinical data are available. As AED concentrations traditionally are given in $\mu \mathrm{mol} / \mathrm{L}$, we suggest using the same unit of measurement also for perampanel. The suggested reference range, thus, is $0.25-2.85 \mu \mathrm{mol} / \mathrm{L}(86-1,000 \mathrm{ng} / \mathrm{mL}$ or $0.1-1 \mathrm{mg} / \mathrm{L})$.

\section{Phenobarbital}

All laboratories in Norway state $50-130 \mu \mathrm{mol} / \mathrm{L}(12-30 \mathrm{mg} / \mathrm{L})$ as the reference range. ILAE (2008) and Patsalos and Berry suggest $43-172 \mu \mathrm{mol} / \mathrm{L}(10-40 \mathrm{mg} / \mathrm{L}) .{ }^{5,9}$ ILAE points out, however, that sedation frequently occurs above $130 \mu \mathrm{mol} / \mathrm{L}$ (30 $\mathrm{mg} / \mathrm{L})$. Data from the routine databases at St Olavs University Hospital, Haukeland University Hospital and the National Center for Epilepsy confirm that concentrations exceeding $130 \mu \mathrm{mol} / \mathrm{L}(30 \mathrm{mg} / \mathrm{L})$ are rarely seen. We suggest keeping the existing reference range.

\section{Phenytoin}

The current reference range of $40-80 \mu \mathrm{mol} / \mathrm{L}(10-20 \mathrm{mg} / \mathrm{L})$ is well established and has been used for decades. ILAE as well as Patsalos and Berry also state this reference range. ${ }^{5,9}$ Thus, we suggest no changes. Some laboratories offer measurement of free (unbound) phenytoin. Phenytoin is highly proteinbound, and only the unbound portion is pharmacologically active. Measurement of free phenytoin may be useful in situations where the serum concentration of total phenytoin does not correlate well with the clinical picture and where a higher-than-normal free proportion of phenytoin might be suspected, for example, in patients with albumin deficiency, or in case of suspected interaction with other highly proteinbound drugs. At common doses/serum concentrations, the free portion of phenytoin usually does not exceed $10 \%$ of the total phenytoin concentration. ${ }^{21}$

\section{Pregabalin}

The current reference range is $10-30 \mu \mathrm{mol} / \mathrm{L}(2-5 \mathrm{mg} / \mathrm{L})$. This range was derived from pharmacokinetic calculations based on doses used in clinical studies. We did not find recommendations in the literature. The Epilepsy Hospital in Dianalund, Denmark, uses 10-35 $\mu \mathrm{mol} / \mathrm{L}(2-6 \mathrm{mg} / \mathrm{L}$; J Borg Rasmussen, personal communication), while the epilepsy center in Bethel, Germany, uses 12.6-31 $\mu \mathrm{mol} / \mathrm{L}$ $(2-5 \mathrm{mg} / \mathrm{L}) .{ }^{18}$ Indeed, the majority of patients have serum concentrations within these ranges, but in a Norwegian study $(\mathrm{n}=167), 18 \%$ of the patients had higher concentrations. ${ }^{28}$

An estimated $95 \%$ of all pregabalin prescriptions are for neuropathic pain treatment where there is no tradition for TDM, but rather dosing according to effect or dosing schemes. ${ }^{1,41}$ There is no available clinical data allowing to establish a reference range. However, pregabalin clearly has a potential for misuse, ${ }^{42-44}$ and, thus, it is desirable to have a reference range. Our recommendation is to adjust the upper limit and use 10-35 $\mu \mathrm{mol} / \mathrm{L} \mathrm{(2-6} \mathrm{mg/L).}$

\section{Rufinamide}

The current Norwegian reference range is $20-130 \mu \mathrm{mol} / \mathrm{L}$ $(5-31 \mathrm{mg} / \mathrm{L})$. The reference range used in Denmark is 15-90 $\mu \mathrm{mol} / \mathrm{L}$ (4-21 mg/L), mainly based on clinical experience ( $\mathrm{J}$ Borg Rasmussen, personal communication) and in Germany, 21-126 $\mu \mathrm{mol} / \mathrm{L}$ (5-30 mg/L; Bethel). ${ }^{18}$ A review by Perucca et al, based on unpublished data from the manufacturer, reports that concentrations needed to reduce seizure frequency by $25 \%-50 \%$ range between 63 and $126 \mu \mathrm{mol} / \mathrm{L}$ (15-30 mg/L). ${ }^{45}$ Patients with Lennox-Gastaut syndrome seem to need concentrations up to $210 \mu \mathrm{mol} / \mathrm{L}(50 \mathrm{mg} / \mathrm{L})$. The authors state that a concentration of $126 \mu \mathrm{mol} / \mathrm{L}(30 \mathrm{mg} / \mathrm{L})$ is higher than most patients will reach in clinical practice. The above-mentioned numbers were not obtained by clinical observation, but by pharmacokinetic-pharmacodynamic modeling. We suggest a lower limit according to the Danish experience; hence, the (still preliminary) reference range would be $15-130 \mu \mathrm{mol} / \mathrm{L}$ (4-31 mg/L).

\section{Stiripentol}

Stiripentol is a challenging AED because of saturation kinetics, 99\% protein binding and various drug interactions. ${ }^{4,21}$ Patsalos and Berry cite one study that found therapeutic effect in the range of $17-94 \mu \mathrm{mol} / \mathrm{L}(4-22 \mathrm{mg} / \mathrm{L}) .{ }^{46}$ The Epilepsy Hospital in Dianalund, Denmark, uses 15-95 $\mu \mathrm{mol} / \mathrm{L}$ (4-22 mg/L; J Borg Rasmussen, personal communication), while the epilepsy center in Bethel, Germany, uses 4-43 $\mu \mathrm{mol} / \mathrm{L}(1-10 \mathrm{mg} / \mathrm{L}) .{ }^{18}$ We suggest $15-95 \mu \mathrm{mol} / \mathrm{L}$ (4-22 mg/L), as supported by clinical data.

\section{Sulthiame}

Sulthiame was introduced in the 1960s and has been little or not used in most countries. However, in recent years, it 
has gained popularity. In Germany, it has long been used as first-choice AED in children with self-limited epilepsy with centrotemporal spikes, and as a second choice in other focal epilepsies and in infantile spasms. ${ }^{20}$ Bethel uses a reference range of 7-28 $\mu \mathrm{mol} / \mathrm{L}(2-8 \mathrm{mg} / \mathrm{L})$, while in Kork, 3.5-10.5 $\mu \mathrm{mol} / \mathrm{L}(1-3 \mathrm{mg} / \mathrm{L})$ and $17.5-35 \mu \mathrm{mol} / \mathrm{L}$ $(5-10 \mathrm{mg} / \mathrm{L})$ are used, depending on the type of seizure. ${ }^{18,20}$ In Dianalund, 5-35 $\mu \mathrm{mol} / \mathrm{L}$ is used $(2-10 \mathrm{mg} / \mathrm{L}$; J Borg Rasmussen, personal communication). Our recommendation is $5-35 \mu \mathrm{mol} / \mathrm{L}(2-10 \mathrm{mg} / \mathrm{L})$, where the lower limit is identical to the Danish one, and between the two German ones.

\section{Topiramate}

All laboratories in Norway state $15-60 \mu \mathrm{mol} / \mathrm{L}(5-20 \mathrm{mg} / \mathrm{L})$ as the reference range, which is in accordance with the ILAE guideline. ${ }^{5}$ The Epilepsy Hospital in Dianalund, however, uses a somewhat lower range of $6-30 \mu \mathrm{mol} / \mathrm{L}(2-10 \mathrm{mg} / \mathrm{L})$. This is based on a clinical study by Christensen et al and routine TDM data (J Borg Rasmussen, personal communication). ${ }^{47}$ The Bethel epilepsy center uses 6-24 $\mu \mathrm{mol} / \mathrm{L}(2-8 \mathrm{mg} / \mathrm{L})$; also this is based on own clinical data. ${ }^{18,48}$ Routine TDM data from St Olavs University Hospital show indeed that the mid $80 \%$ of all serum concentrations fall between 7 and $38 \mu \mathrm{mol} / \mathrm{L}$ (2-13 mg/L; unpublished data). Similar findings have been documented at the National Center for Epilepsy. ${ }^{37}$ The ILAE guideline states that more recently, lower doses are used than immediately after introduction of topiramate. ${ }^{5}$ A lower limit of $6 \mu \mathrm{mol} / \mathrm{L}(2 \mathrm{mg} / \mathrm{L})$, therefore, appears adequate, while an upper limit of $30 \mu \mathrm{mol} / \mathrm{L}(10 \mathrm{mg} / \mathrm{L})$ would fall between the upper limit in Bethel and the 90 percentile from St Olavs Hospital. Our recommendation is, therefore, 6-30 $\mu \mathrm{mol} / \mathrm{L}(2-10 \mathrm{mg} / \mathrm{L})$.

\section{Valproate}

In Norway, both 250 and $300 \mu \mathrm{mol} / \mathrm{L}$ ( 36 and $43 \mathrm{mg} / \mathrm{L}$ ) were used as the lower limit, while 600 and $700 \mu \mathrm{mol} / \mathrm{L}$ (87 and $100 \mathrm{mg} / \mathrm{L}$ ) were stated as the upper limit. Most international text books as well as review articles state $347 \mu \mathrm{mol} / \mathrm{L}$ $(50 \mathrm{mg} / \mathrm{L})$ as the lower limit, and either $694 \mu \mathrm{mol} / \mathrm{L}$ $(100 \mathrm{mg} / \mathrm{L})$ or $867 \mu \mathrm{mol} / \mathrm{L}(125 \mathrm{mg} / \mathrm{L})$ as the upper. Overdosing of valproate produces generally mild and quickly reversible symptoms such as tremor and sedation. We, therefore, recommend an upper limit of $700 \mu \mathrm{mol} / \mathrm{L}(101 \mathrm{mg} / \mathrm{L})$. A recent study showed that valproate's pharmacokinetic variability in women is extensive. The authors recommend that serum concentrations (both total and free valproate) should be monitored for improved safety in women. ${ }^{49}$ Measurement of free (unbound) valproate is available at some laboratories.
It can be useful in situations where the serum concentration of total valproate does not correlate with the clinical picture, for example, in patients with albumin deficiency, during pregnancy or in case of suspected interaction with other highly protein-bound drugs. At common doses and serum concentrations, the free fraction of valproate usually does not exceed $10 \%$ of the total valproate concentration. ${ }^{21}$

\section{Vigabatrin}

At doses from 1,000 to $3,000 \mathrm{mg} / \mathrm{d}$, serum concentrations ranging from 6 to $279 \mu \mathrm{mol} / \mathrm{L}(0.8-36 \mathrm{mg} / \mathrm{L})$ have been reported. ${ }^{5}$ This range demonstrates a very large pharmacokinetic variation (dose varies by a factor of 3 , while serum concentration varies by a factor of 47). Being an irreversible inhibitor of the enzyme GABA-transaminase, vigabatrin is a hit-and-run drug. That means that its pharmacologic effect lasts longer than its plasma half-life would imply. For that reason, vigabatrin's clinical effect does not correlate with its serum concentration. It is, thus, neither possible nor suitable to state a reference range for vigabatrin.

\section{Zonisamide}

The current reference range in Norway is $45-180 \mu \mathrm{mol} / \mathrm{L}$ (10-40 mg/L), which is identical with ILAE's proposal and close to the ranges used in Dianalund (J Borg Rasmussen, personal communication), Bethel and Kork. ${ }^{18,20}$ While the upper limits of the German centers are close to the ILAE recommendation, the lower limits are more divergent. We suggest keeping the current reference range unchanged, because the lower limit is in accordance with the ILAE guideline and between the values used by the two German centers.

\section{Usefulness of TDM}

The usefulness of TDM of AEDs has been discussed controversially for decades. Interestingly, an AED, phenytoin, was among the first drugs that made TDM popular, because of its dose-dependent kinetics. ${ }^{50}$ Experience shows that TDM is most useful in given clinical situations. ${ }^{5}$ This means that the blood sample is taken with a certain question in mind that the serum concentration shall help to answer. Clinical situations where TDM can be useful include lack of therapeutic effect despite an adequate dose, adverse effect despite a low dose, altered pharmacokinetics due to pregnancy, liver or kidney disease, microbial infection, suspected drug interaction, known or suspected pharmacogenetic mutations, and more. The value of routine TDM without a clinical reason is indeed doubtful. ${ }^{4,51-53}$ It must also be emphasized that TDM is not the drug concentration 
measurement only, as TDM in addition provides expert clinical interpretation..$^{54}$

Clinical experience shows that reference ranges are not always used the way they are supposed to, which may be one reason why there is a lack of studies that support the usefulness of TDM in epilepsy treatment. ${ }^{52}$ One of several common misconceptions is that a concentration within the reference range will always give the desired clinical effect. ${ }^{55}$ Similarly, a serum concentration below the reference range is acceptable if the patient is seizure free. Arbitrary, outdated and divergent reference ranges for the same drug may cause misunderstandings, which may contribute to suboptimal use and reinforce the skepticism toward the concept of TDM. ${ }^{5,56}$

\section{Methodologic considerations and limitations}

Due to a general lack of sufficient data, this report cannot consider all possible clinical consequences of polytherapy including pharmacodynamic and pharmacokinetic interactions. Clinical evaluation and observant follow-up of the patient must, therefore, be the leading element, as in all medical treatment.

Most suggested reference ranges are tentative and many are poorly documented. Several are supported by broad clinical experience and population-based data from pharmacologic laboratories, but only few are based on systematic investigations of correlations between clinical data and serum concentrations. A Cochrane review only found one randomized controlled trial comparing the outcomes of AED monotherapy guided by TDM with drug treatment without the aid of TDM. ${ }^{53}$ All types of documentation are hampered by limitations, and further adjustments of reference ranges based on future studies must be anticipated. Moreover, seizure type, severity and frequency, as well as epilepsy syndrome, age, comorbidity and comedication may influence the efficacy and tolerability of AEDs in the individual patient. For example, clinical experience shows that patients with pre-existing cognitive deficits are often more vulnerable to cognitive side effects than other patients. ${ }^{57-60}$ Nevertheless, most individual therapeutic ranges should fall within the suggested population-based reference ranges.

Routine data from pharmacologic laboratories in Norway support many of the proposed reference ranges in this report, but these data include cases where TDM was performed because of loss of seizure control, adverse effects, suspected nonadherence or other adverse clinical circumstances.
Nonetheless, in cases where no sufficient clinical data are available, we believe that after cutting off the extreme values at both ends by using only the central portion, for example, the central $80 \%$ or $90 \%$ of the distribution curve, such routine data are robust enough to establish preliminary reference ranges, at least in the country where they have been collected. As the example of lamotrigine shows (Lamotrigine in Results section), different national treatment traditions may lead to different dosing and, thus, different average serum concentrations. . $^{34,35}$

\section{Significance}

We found several AEDs with diverging reference ranges in Norway. Laboratories in different parts of Norway should not state different reference ranges, because treatment traditions and health care services are equal across the country. Discrepancies in reference ranges could confuse prescribers and lead to unnecessary, potentially harmful alterations in patient treatment. Harmonized reference ranges render the process of staying updated to a national concern and oblige every laboratory to share new information and research that could be of importance, and in turn lead to changes of AED reference ranges. In a small country like Norway, interlaboratory cooperation makes it possible to stay updated in a world where medical knowledge is subjected to rapid changes. Harmonizing reference ranges is the first step to create joint reference manuals for laboratories. These reference manuals provide information to clinicians and laboratory personnel on how to do sampling, and how to interpret analytic results. National reference manuals render the continuous work with updating information an interlaboratory collaboration - saving resources and being an assurance of quality of the information given. This also contributes to improve pharmacovigilance and facilitates the clinical implementation of TDM.

\section{Acknowledgment}

The authors thank Jan Borg Rasmussen, head of the clinicalpharmacological laboratory at the Epilepsy Hospital Filadelfia in Dianalund, Denmark, for discussions and useful comments.

\section{Disclosure}

All authors except EB work at state-owned laboratories that offer measurement of serum concentrations of drugs, including antiepileptic drugs. None of the authors are gaining any financial profit from this paper. The authors report no conflicts of interest in this work. 


\section{References}

1. Baftiu A, Johannessen Landmark C, Rusten IR, Feet SA, Johannessen SI, Larsson PG. Changes in utilisation of antiepileptic drugs in epilepsy and non-epilepsy disorders-a pharmacoepidemiological study and clinical implications. Eur J Clin Pharmacol. 2016;72(10):1245-1254.

2. Landmark CJ, Fossmark H, Larsson PG, Rytter E, Johannessen SI. Prescription patterns of antiepileptic drugs in patients with epilepsy in a nation-wide population. Epilepsy Res. 2011;95(1-2):51-59.

3. Norwegian Prescription Database. Available from: www.norpd.no. Accessed July 30, 2017.

4. Landmark CJ, Johannessen SI, Tomson T. Dosing strategies for antiepileptic drugs: from a standard dose for all to individualised treatment by implementation of therapeutic drug monitoring. Epileptic Disord. 2016;18(4):367-383.

5. Patsalos PN, Berry DJ, Bourgeois BF, et al. Antiepileptic drugs-best practice guidelines for therapeutic drug monitoring: a position paper by the subcommission on therapeutic drug monitoring, ILAE Commission on Therapeutic Strategies. Epilepsia. 2008;49(7):1239-1276.

6. Katayev A, Balciza C, Seccombe DW. Establishing reference intervals for clinical laboratory test results: is there a better way? Am J Clin Pathol. 2010;133(2):180-186.

7. Epilepsy CoADotILA. Guidelines for clinical evaluation of antiepileptic drugs. Epilepsia. 1989;30(4):400-408.

8. Karlsen Bjanes T, Mjaset Hjerto E, Lonne L, et al. Pharmacology portal: an open database for clinical pharmacologic laboratory services. Clin Ther. 2016;38(1):222-226.

9. Patsalos PN, Berry DJ. Therapeutic drug monitoring of antiepileptic drugs by use of saliva. Ther Drug Monit. 2013;35(1):4-29.

10. Felles nasjonale referanseområder for antiepileptika. Farmakologiportalen [Joint national reference ranges for antiepileptic drugs]. Available from: http://www.farmakologiportalen.no/nasjonale_ referanseomrader/\#index1. Accessed November 22, 2017. Norwegian.

11. Reimers A, Berg JA, Burns ML, Landmark CJ. Harmonised reference ranges for antiepileptic drugs. Tidsskr Nor Laegeforen. 2017; 137(12-13):864-865.

12. Hiemke C, Bergemann N, Clement HW, et al. Consensus guidelines for therapeutic drug monitoring in neuropsychopharmacology: update 2017. Pharmacopsychiatry. Epub 2017 Sep 14.

13. Steinhoff BJ, Bacher M, Bucurenciu I, et al. Real-life experience with brivaracetam in 101 patients with difficult-to-treat epilepsy-A monocenter survey. Seizure. 2017;48:11-14.

14. Stockis A, Chanteux H, Rosa M, Rolan P. Brivaracetam and carbamazepine interaction in healthy subjects and in vitro. Epilepsy Res. 2015; 113:19-27.

15. Strzelczyk A, Steinig I, Willems LM, et al. Treatment of refractory and super-refractory status epilepticus with brivaracetam: a cohort study from two German university hospitals. Epilepsy Behav. 2017;70(Pt A): $177-181$.

16. Stockis A, Watanabe S, Rouits E, Matsuguma K, Irie S. Brivaracetam single and multiple rising oral dose study in healthy Japanese participants: influence of CYP2C19 genotype. Drug Metab Pharmacokinet. 2014;29(5):394-399.

17. Schoemaker R, Wade JR, Stockis A. Brivaracetam population pharmacokinetics and exposure-response modeling in adult subjects with partial-onset seizures. J Clin Pharmacol. 2016;56(12):1591-1602.

18. Therapeutische Bereiche. Available from: http://www.epilepsieforschung.de/fileadmin/_migrated/content_uploads/TherapeutischeBereiche.pdf. Accessed March 30, 2017.

19. Sidenius P, Hjalgrim H. Antiepileptika; 2017. Available from: https:// pro.medicin.dk/Laegemiddelgrupper/Grupper/315545. Accessed July 14, 2017.

20. Steinhoff B, Bast T. Compendium Antiepileptic Drugs. Berlin: Deutsche Gesellschaft für Epileptologie; 2017/2018.

21. Patsalos PN, Zugman M, Lake C, James A, Ratnaraj N, Sander JW. Serum protein binding of 25 antiepileptic drugs in a routine clinical setting: a comparison of free non-protein-bound concentrations. Epilepsia. 2017;58(7):1234-1243.
22. Burns ML, Baftiu A, Opdal MS, Johannessen SI, Landmark CJ. Therapeutic drug monitoring of clobazam and it's metabolite-impact of age and comedication on pharmacokinetic variability. Ther Drug Monit. 2016;38(3):350-357.

23. Debruyne D, Pailliet-Loilier M, Lelong-Boulouard V, Coquerel A, Bentue-Ferrer D. STP du clonazépam [Therapeutic drug monitoring of clonazepam]. Therapie. 2010;65(3):219-224. French.

24. Bialer M, Soares-da-Silva P. Pharmacokinetics and drug interactions of eslicarbazepine acetate. Epilepsia. 2012;53(6):935-946.

25. Svendsen T, Brodtkorb E, Reimers A, et al. Pharmacokinetic variability, efficacy and tolerability of eslicarbazepine acetate-A national approach to the evaluation of therapeutic drug monitoring data and clinical outcome. Epilepsy Res. 2017;129:125-131.

26. Falcao A, Fuseau E, Nunes T, Almeida L, Soares-da-Silva P. Pharmacokinetics, drug interactions and exposure-response relationship of eslicarbazepine acetate in adult patients with partial-onset seizures: population pharmacokinetic and pharmacokinetic/pharmacodynamic analyses. CNS Drugs. 2012;26(1):79-91.

27. Harden CL, Trifiletti R, Kutt H. Felbamate levels in patients with epilepsy. Epilepsia. 1996;37(3):280-283.

28. Johannessen Landmark C, Beiske G, Baftiu A, Burns ML, Johannessen SI. Experience from therapeutic drug monitoring and gender aspects of gabapentin and pregabalin in clinical practice. Seizure. 2015;28:88-91.

29. Gidal BE, Radulovic LL, Kruger S, Rutecki P, Pitterle M, Bockbrader HN. Inter- and intra-subject variability in gabapentin absorption and absolute bioavailability. Epilepsy Res. 2000;40(2-3):123-127.

30. Greenaway C, Ratnaraj N, Sander JW, Patsalos PN. A high-performance liquid chromatography assay to monitor the new antiepileptic drug lacosamide in patients with epilepsy. Ther Drug Monit. 2010;32(4): 448-452.

31. Greenaway C, Ratnaraj N, Sander JW, Patsalos PN. Saliva and serum lacosamide concentrations in patients with epilepsy. Epilepsia. 2011; 52(2):258-263.

32. Svendsen T, Brodtkorb E, Baftiu A, Burns ML, Johannessen SI, Johannessen Landmark C. Therapeutic Drug Monitoring of Lacosamide in Norway: focus on pharmacokinetic variability, efficacy and tolerability. Neurochem Res. 2017;42(7):2077-2083.

33. Contin M, Albani F, Riva R, Candela C, Mohamed S, Baruzzi A. Lacosamide therapeutic monitoring in patients with epilepsy: effect of concomitant antiepileptic drugs. Ther Drug Monit. 2013;35(6): 849-852.

34. Reimers A. Trends and changes in the clinical use of lamotrigine. Pharmacoepidemiol Drug Saf. 2009;18(2):132-139.

35. Morris RG, Lee MY, Cleanthous X, Black AB. Long-term follow-up using a higher target range for lamotrigine monitoring. Ther Drug Monit. 2004;26(6):626-632.

36. Leppik IE, Rarick JO, Walczak TS, Tran TA, White JR, Gumnit RJ. Effective levetiracetam doses and serum concentrations: age effects. Epilepsia. 2002;43 (Suppl 7):240.

37. Johannessen Landmark C, Baftiu A, Tysse I, et al. Pharmacokinetic variability of four newer antiepileptic drugs, lamotrigine, levetiracetam, oxcarbazepine, and topiramate: a comparison of the impact of age and comedication. Ther Drug Monit. 2012;34(4):440-445.

38. Majid O, Laurenza A, Ferry J, Hussein Z. Impact of perampanel on pharmacokinetics of concomitant antiepileptics in patients with partialonset seizures: pooled analysis of clinical trials. Br J Clin Pharmacol. 2016;82(2):422-430.

39. Lloyd P, Flesch G, Dieterle W. Clinical pharmacology and pharmacokinetics of oxcarbazepine. Epilepsia. 1994;35(Suppl 3):S10-S13.

40. Patsalos PN. The clinical pharmacology profile of the new antiepileptic drug perampanel: a novel noncompetitive AMPA receptor antagonist. Epilepsia. 2015;56(1):12-27.

41. Johannessen Landmark C, Larsson PG, Rytter E, Johannessen SI. Antiepileptic drugs in epilepsy and other disorders-a population-based study of prescriptions. Epilepsy Res. 2009;87(1):31-39.

42. Schjerning O, Rosenzweig M, Pottegard A, Damkier P, Nielsen J. Abuse potential of pregabalin: a systematic review. CNS Drugs. 2016; 30(1):9-25. 
43. Westin A, Bramness JG, Chalabianloo F, Rygnestad T, Slørdal T. Pregabalin bør flyttes til reseptgruppe B [Pregabalin should be moved to prescription group B]. Tidsskr Nor Legeforen. 2013;133(6):115-116. Norwegian.

44. Caster O, Edwards IR, Noren GN, Lindquist M. Earlier discovery of pregabalin's dependence potential might have been possible. Eur $J$ Clin Pharmacol. 2011;67(3):319-320.

45. Perucca E, Cloyd J, Critchley D, Fuseau E. Rufinamide: clinical pharmacokinetics and concentration-response relationships in patients with epilepsy. Epilepsia. 2008;49(7):1123-1141.

46. Chiron C, Marchand MC, Tran A, et al. Stiripentol in severe myoclonic epilepsy in infancy: a randomised placebo-controlled syndrome-dedicated trial. STICLO study group. Lancet. 2000;356(9242):1638-1642.

47. Christensen J, Andreasen F, Poulsen JH, Dam M. Randomized, concentration-controlled trial of topiramate in refractory focal epilepsy. Neurology. 2003;61(9):1210-1218.

48. May TW, Rambeck B, Jurgens U. Serum concentrations of topiramate in patients with epilepsy: influence of dose, age, and comedication. Ther Drug Monit. 2002;24(3):366-374.

49. Johannessen Landmark C, Burns ML, Baftiu A, et al. Pharmacokinetic variability of valproate in women of childbearing age. Epilepsia. 2017; 58(10):e142-e146.

50. Richens A, Dunlop A, Ahmad S, Laidlaw J. Monitoring serumphenytoin. Lancet. 1976;1(7961):699-700.

51. Glauser TA, Pippenger CE. Controversies in blood-level monitoring: reexamining its role in the treatment of epilepsy. Epilepsia. 2000; 41 (Suppl 8):S6-S15.
52. Striano S, Striano P, Capone D, Pisani F. Limited place for plasma monitoring of new antiepileptic drugs in clinical practice. Med Sci Monit. 2008;14(10):RA173-RA178.

53. Tomson T, Dahl ML, Kimland E. Therapeutic monitoring of antiepileptic drugs for epilepsy. Cochrane Database Syst Rev. 2007;(1): CD002216.

54. Gross AS. Best practice in therapeutic drug monitoring. Br J Clin Pharmacol. 1998;46(2):95-99.

55. Evans WE. General principles of Pharmacokinetics. In: Burton ME, Shaw LM, Schentag JJ, Evans WE, editors. Applied Pharmacokinetics and Pharmacodynamics: Principles of Therapeutic Drug Monitoring. 4th ed. Baltimore, MD: Lippincott Williams \& Wilkins; 2006.

56. Perucca E. Is there a role for therapeutic drug monitoring of new anticonvulsants? Clin Pharmacokinet. 2000;38(3):191-204.

57. Brodtkorb E. Management of epilepsy in people with intellectual disability. In: Shorvon S, Perucca E, Engel J, editors. The Treatment of Epilepsy. 4th ed. Oxford: John Wiley \& Sons; 2016:199-205.

58. Grevers E, Breuer LE, DM IJ, Aldenkamp AP. Mental slowing in relation to epilepsy and antiepileptic medication. Acta Neurol Scand. 2016;134(2):116-122.

59. Helmstaedter C, Wagner G, Elger CE. Differential effects of first antiepileptic drug application on cognition in lesional and non-lesional patients with epilepsy. Seizure. 1993;2(2):125-130.

60. Witt JA, Elger CE, Helmstaedter C. Impaired verbal fluency under topiramate-evidence for synergistic negative effects of epilepsy, topiramate, and polytherapy. Eur J Neurol. 2013;20(1):130-137.
Drug Design, Development and Therapy

\section{Publish your work in this journal}

Drug Design, Development and Therapy is an international, peerreviewed open-access journal that spans the spectrum of drug design and development through to clinical applications. Clinical outcomes, patient safety, and programs for the development and effective, safe, and sustained use of medicines are the features of the journal, which

\section{Dovepress}

has also been accepted for indexing on PubMed Central. The manuscript management system is completely online and includes a very quick and fair peer-review system, which is all easy to use. Visit http://www.dovepress.com/testimonials.php to read real quotes from published authors. 